TI 2016-020/VII

Tinbergen Institute Discussion Paper

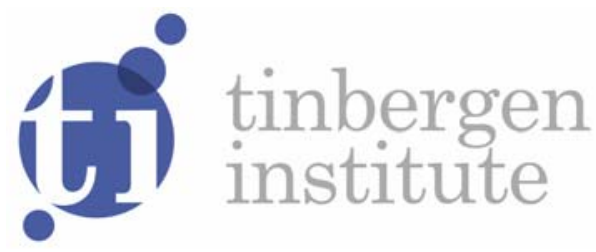

\title{
Market Structure and Advance Selling
}

\author{
Marc Möller
}

Makoto Watanabe 2

1 University of Bern, Switzerland;

2 Faculty of Economics and Business Administration, VU University Amsterdam, and Tinbergen Institute, the Netherlands; 
Tinbergen Institute is the graduate school and research institute in economics of Erasmus University Rotterdam, the University of Amsterdam and VU University Amsterdam.

More TI discussion papers can be downloaded at http://www.tinbergen.nl

Tinbergen Institute has two locations:

Tinbergen Institute Amsterdam

Gustav Mahlerplein 117

1082 MS Amsterdam

The Netherlands

Tel.: +31(0)20525 1600

Tinbergen Institute Rotterdam

Burg. Oudlaan 50

3062 PA Rotterdam

The Netherlands

Tel.: +31(0)10 4088900

Fax: +31(0)10 4089031 


\title{
Market Structure and Advance Selling
}

\author{
Marc Möller*
}

\author{
Makoto Watanabe ${ }^{\dagger}$
}

\begin{abstract}
When products are sold in advance, i.e. prior to consumption, consumers trade off an early, uninformed purchase at a low price against a late, informed purchase at a high price. This paper considers the effect of market structure on the prevalence of advance selling. We show that in an oligopolistic market with multi-product firms, advance selling (with its associated allocative inefficiency) is decreasing in market concentration when the consumers' preference uncertainty is high but can be increasing when uncertainty is low.
\end{abstract}

Keywords: Competition, Price Discrimination, Individual Demand Uncertainty, Advance Purchase Discounts.

JEL: D43, D80, L13.

\section{Introduction}

In a variety of markets, firms offer advance purchase discounts to those consumers who buy prior to consumption, i.e. with potentially imperfect information about their preferences. The most prominent example for this practice is the airline industry where ticket prices increase as the departure date approaches. Due to the associated risk of a mismatch between consumer preferences and product characteristics, advance selling constitutes a potential source of allocative inefficiency. From a regulatory viewpoint it is therefore important to understand the determinants of this practice.

*Department of Economics, University of Bern, Schanzeneckstrasse 1, 3001 Bern, Switzerland. Email: marc.moeller@vwi.unibe.ch, Tel.: +41-(0)31631-8078, Fax: +41-(0)31631-3783 .

${ }^{\dagger}$ Department of Economics, FEWEB, VU University Amsterdam, Tinbergen Institute, Address: Department of Economics, VU Amsterdam, De Boelelaan 1105, NL-1081 HV Amsterdam, The Netherlands, makoto.wtnb@gmail.com, Tel.: +31-20598-6030, Fax: +31-20598-9870. 
An open issue is how advance selling depends on market structure. ${ }^{1}$ Gale (1993) and Möller and Watanabe (2016) have provided a partial answer to this question by showing that a duopoly exhibits more advance selling than a monopoly. Duopolists engage in inter-temporal business stealing by capturing customers early, i.e. before they can develop a preference for a rival's product. One might therefore be tempted to conclude that there exists a monotone relationship between competition and advance selling. In this paper we argue that increasing the number of firms beyond duopoly can have an adverse effect on advance selling.

We consider a market with a given number of products (e.g. flights) which are offered by a varying number of multi-product firms (e.g. airlines). The benefit of this approach is that it allows us to determine the influence of market structure on advance selling in isolation of its effect on the consumers' degree of preference uncertainty. We show that advance selling increases monotonically with the number of firms when uncertainty is above a certain threshold. However, below this threshold, the relation between market concentration and advance selling turns out to be inverse U-shaped. This occurs because for low levels of preference uncertainty the benefits of capturing customers are rather low so that a reduction in the firms' profit margin due to stronger competition reduces their incentive to engage in inter-temporal business stealing.

Our theory explains the influence of oligopolistic market structure on (inter-temporal) price dispersion. It can therefore help to shed light on a recent empirical controversy concerned with the question of whether price dispersion can serve as an indicator of an industry's competitive conduct. Collecting internet fare data posted at different times before departure, Gaggero and Piga (2011) find that flights on more competitive routes exhibit a smaller degree of inter-temporal price dispersion. This is in line with the negative relation between competition and price dispersion found by Gerardi and Shapiro (2009) but contrasts with the positive relation documented by Borenstein and Rose (1994) and Stavins (1996), or the inverse U-shaped relation in Dai et al. (2014). Our theory encompasses these findings and identifies demand uncertainty as a key element in the interpretation of price dispersion as a positive or negative sign for competitive conduct.

\section{Model}

We consider a market with a fixed number $n \geq 4$ of differentiated products which are produced by a variable number $m \geq 2$ of identical firms. ${ }^{2}$ We denote by $\kappa=\frac{n}{m}$ the

\footnotetext{
${ }^{1}$ Most of the literature on advance selling has focused on the polar cases of monopoly or perfect competition. See Gale and Holmes (1993), DeGraba (1995), Courty and Li (2000), Courty (2003), Möller and Watanabe (2010), and Nocke, Peitz, and Rosar (2011) for monopoly and Dana (1998) for perfect competition.

${ }^{2}$ In reality, a change in the number of competitors might be accompanied by a change in the number of products. This may affect the consumers' preference uncertainty. Holding the number of
} 
number of products supplied by each firm. ${ }^{3}$ There exists a continuum of consumers with mass one. For each consumer there exists one product which he prefers over all others. A consumer obtains the value $s+\sigma$ from consuming his preferred product. The value of consuming any other product is given by $s$. Following most of the literature on price competition in differentiated product markets we let $s$ be sufficiently large for the market to be covered. Consumers differ in their choosiness $\sigma \in[0,1]$. The additional utility from consuming their preferred product rather than a non-preferred product is greater for more choosy consumers. We assume that $\sigma$ is uniformly distributed in $[0,1]$.

There are two periods. In period 1 each consumer privately receives an imperfect but informative signal about the identity of his preferred product. In period 2, consumers learn the true identity of their preferred product. The product indicated by the signal in period 1 will be called the consumer's favorite product. With probability $\gamma \in\left(\frac{1}{n}, 1\right)$ the signal is correct in that the consumer's favorite product turns out to be his preferred product. With probability $1-\gamma$ the signal is wrong, pointing to any one of the consumer's non-preferred products. The parameter $\gamma$ measures the consumers' common degree of individual demand uncertainty. For $\gamma \rightarrow \frac{1}{n}$ the consumers' signal becomes uninformative and consumers face maximal uncertainty. For $\gamma \rightarrow 1$ individual demand uncertainty becomes negligible and consumers know their preferences already in period 1.

Firms produce with a constant marginal cost which we normalize to zero. They can commit to prices in advance. More specifically, in period 1 each firm chooses a price schedule for each of its products determining the product's price in both periods. ${ }^{4}$ Since consumers prefer an informed purchase over an uninformed purchase we can, without loss of generality, restrict the firms strategy space to consist of non-decreasing price schedules.

\section{Result}

In the following we derive the unique candidate for a symmetric pure-strategy equilibrium $\left(p_{1}^{*}, p_{2}^{*}\right)$ in which firms practice inter-temporal price discrimination by selling a positive quantity in both periods. For this purpose, suppose that all firms choose the price schedule $\left(p_{1}^{*}, p_{2}^{*}\right)$ for all of their products and firm $i$ deviates by offering its pro$\operatorname{duct}(\mathrm{s})$ at prices $\left(p_{1}, p_{2}\right)$. Further suppose that $p_{1}<p_{1}^{*}$ so that in period 1 , a consumer

products constant allows us to elicit the influence of competition on advance selling for a given level of preference uncertainty. This is in accordance with the empirical studies which control for the number of flights on a given route.

${ }^{3}$ To guarantee that $\kappa$ is integer let $n=2^{N}$ with $N \geq 2$ integer and $m=2^{M}$ with $M \in$ $\{1,2,3, \ldots, N-1\}$.

${ }^{4}$ In a related but monopolistic setting, more sophisticated selling schemes such as refund contracts have been shown to be the optimal (Courty and Li (2000)). Our focus on price posting resonates well with the empirical work on airline price dispersion which restricts attention to non-refundable tickets. 
with a favorite offered by firm $j \neq i$ prefers buying one of the cheaper products offered by firm $i$ if and only if

$$
s+\frac{1-\gamma}{n-1} \sigma-p_{1}>s+\gamma \sigma-p_{1}^{*} \Leftrightarrow \sigma<\left(p_{1}^{*}-p_{1}\right) \frac{n-1}{\gamma n-1} \equiv \bar{\sigma} .
$$

Consumers who wait until period 2 will purchase their preferred product, since otherwise they could have purchased in period 1 at a lower price. A consumer with a favorite produced by firm $i$ will prefer a product produced by a different firm $j$ with probability $r_{i} \equiv(1-\gamma) \frac{n-\kappa}{n-1}$. Such a consumer will therefore wait until period 2 if and only if

$$
s+\sigma-\left(1-r_{i}\right) p_{2}-r_{i} p_{2}^{*}>s+\gamma \sigma-p_{1} \Leftrightarrow \sigma>\frac{r_{i} p_{2}^{*}+\left(1-r_{i}\right) p_{2}-p_{1}}{1-\gamma} \equiv \sigma_{W, i} .
$$

Similarly, a consumer with a favorite produced by firm $j$ will turn out to prefer a product offered by firm $i$ with probability $r_{j} \equiv(1-\gamma) \frac{\kappa}{n-1}$. Such a consumer will therefore wait until period 2 iff

$$
s+\sigma-r_{j} p_{2}-\left(1-r_{j}\right) p_{2}^{*}>s+\gamma \sigma-p_{1}^{*} \Leftrightarrow \sigma>\frac{\left(1-r_{j}\right) p_{2}^{*}+r_{j} p_{2}-p_{1}^{*}}{1-\gamma} \equiv \sigma_{W, j} .
$$

For small deviations from the equilibrium schedule it has to hold that $0<\bar{\sigma}<$ $\min \left(\sigma_{W, i}, \sigma_{W, j}\right)<1$ and firm $i$ 's profit is given by

$$
\Pi_{i}=p_{1}\left[\frac{1}{m} \sigma_{W, i}+\left(1-\frac{1}{m}\right) \bar{\sigma}\right]+p_{2}\left[\frac{1}{m}\left(1-r_{i}\right)\left(1-\sigma_{W, i}\right)+\left(1-\frac{1}{m}\right) r_{j}\left(1-\sigma_{W, j}\right)\right] .
$$

Firm $i$ 's first period demand consists of two groups of consumers: (1) those who favor one of firm $i$ 's products and are not choosy enough to wait; and (2) those who favor a rival's product but are not choosy enough to pay a higher price for it. Firm i's second period demand consists of those consumers who were choosy enough to buy late. Again we can distinguish two groups of consumers: (1) those who favored one of $i$ 's products before and still prefer one of $i$ 's products; and (2) those who favored another firm's product before but now prefer a product of firm $i$.

For $\left(p_{1}^{*}, p_{2}^{*}\right)$ to be an equilibrium, the derivatives of profits with respect to $p_{1}$ and $p_{2}$ have to be zero at $\left(p_{1}, p_{2}\right)=\left(p_{1}^{*}, p_{2}^{*}\right)$. Hence $\left(p_{1}^{*}, p_{2}^{*}\right)$ can be uniquely determined from the corresponding linear system of first order conditions. In the Appendix we use the prices $\left(p_{1}^{*}, p_{2}^{*}\right)$ to perform comparative statics on the resulting fraction of advance sales

$$
\sigma_{W}^{*}=\frac{p_{2}^{*}-p_{1}^{*}}{1-\gamma}
$$

Proposition 1 In a (symmetric) pure strategy equilibrium, the fraction of advance sales $\sigma_{W}^{*}$ is monotonically decreasing in market concentration $\kappa$ when preference uncertainty is high $(\gamma \leq \underline{\gamma})$, monotonically increasing when preference uncertainty is low $(\gamma \geq \bar{\gamma})$, and has inverted $U$-shape in an intermediate range $(\underline{\gamma}<\gamma<\bar{\gamma})$. 
Proposition 1 shows that for relatively high degrees of uncertainty an increase in competition leads to an increase in advance selling. This is illustrated in Figure 1. Competition decreases the low prices charged to early (unchoosy) buyers while relatively high prices are maintained for late (choosy) buyers. ${ }^{5}$ As a result, advance purchase discounts become larger and more consumers purchase in advance.

A very different picture emerges for relatively low degrees of uncertainty. As can be seen from Figure 2, competition reduces both prices together with the price spread. This is in line with the evidence provided by Gaggero and Piga (2011) and implies that advance selling decreases with competition.

To understand the intuition for Proposition 1 note that an increase in the number of firms has two effects. First, it increases the likelihood that a consumer favoring a particular firm turns out to prefer a rival's product in the future, thereby strengthening the firms' incentive to capture customers in advance. Second, an increase in competition decreases the average price firms charge to their customers, making it less profitable for firms to increase their sales through a discount. Note that the first effect vanishes when preference uncertainty is low whereas the second effect becomes negligible when preference uncertainty is high. With high uncertainty products appear as homogeneous in advance, leading to marginal cost pricing independently of the number of firms. Hence, for low uncertainty competition reduces advance selling due to its negative effect on the price level, whereas for high uncertainty competition increases advance selling due to its positive effect on the likelihood to loose future customers.

\section{Conclusion}

In a recent empirical study of the US airline industry, Lazarev (2013) calculates that the allocative inefficiency resulting from inter-temporal price discrimination amounts to $6 \%$ of overall welfare on monopoly routes. Our theory suggests that still larger inefficiencies can be expected on routes served by more than one airline. An empirical investigation of the allocative inefficiency of advance selling and its dependence on market structure therefore constitutes an important issue for future research.

\section{Appendix}

Proof of Proposition 1: For $\left(p_{1}^{*}, p_{2}^{*}\right)$ to be an equilibrium, the derivatives of the profits in (4) must be zero at $\left(p_{1}, p_{2}\right)=\left(p_{1}^{*}, p_{2}^{*}\right)$ :

$$
0=\frac{p_{2}^{*}-p_{1}^{*}}{1-\gamma}+\left[p_{1}^{*}-\left(1-r_{i}\right) p_{2}^{*}\right] \frac{\partial \sigma_{W, i}}{\partial p_{1}}+p_{1}^{*}(m-1) \frac{\partial \bar{\sigma}}{\partial p_{1}}
$$

\footnotetext{
${ }^{5}$ This can be interpreted as a realization of the brand-loyalty effect suggested by Borenstein (1985) and Holmes (1989) in a setting characterized by inter-temporal price discrimination.
} 


$$
0=1-\frac{p_{2}^{*}-p_{1}^{*}}{1-\gamma}+\left[p_{1}^{*}-\left(1-r_{i}\right) p_{2}^{*}\right] \frac{\partial \sigma_{W, i}}{\partial p_{2}}-p_{2}^{*}(m-1) r_{j} \frac{\partial \sigma_{W, j}}{\partial p_{2}}
$$

Inserting the threshold derivatives, substituting $p_{2}^{*}=p_{1}^{*}+\Delta p^{*}$ with the premium $\Delta p^{*} \equiv p_{2}^{*}-p_{1}^{*}$, and using the fact that $r_{i}=(m-1) r_{j}$ gives:

$$
\begin{aligned}
0 & =\left(2-r_{i}\right) \Delta p^{*}-\left[r_{i}+(m-1)(n-1) \frac{1-\gamma}{\gamma n-1}\right] p_{1}^{*} \\
1-\gamma & =\left[1+\left(1-r_{i}\right)^{2}+r_{i} r_{j}\right] \Delta p^{*}-\left[r_{i}\left(1-r_{i}\right)-r_{i} r_{j}\right] p_{1}^{*} .
\end{aligned}
$$

Solving this linear system of equations, we obtain the equilibrium premium:

$$
\Delta p^{*}=\left[\frac{2}{1-\gamma}-\frac{r_{i}}{1-\gamma}\left(1+\frac{\gamma n-1}{n-1}\right)-\frac{\frac{\gamma n-1}{1-\gamma} \frac{2-r_{i}}{n-1}\left(\frac{n}{n-1}-\frac{r_{i}}{1-\gamma}\right)}{\frac{n}{n-1}-\frac{r_{i}}{1-\gamma}+\frac{n-1}{\gamma n-1}}\right]^{-1} .
$$

Treating $\kappa$ as a continuous variable, we now show that for any $\kappa$ there exists a threshold $\gamma(\kappa)$ such that $\frac{\partial \Delta p^{*}}{\partial \kappa}>0$ if $\gamma>\gamma(\kappa)$ and $\frac{\partial \Delta p^{*}}{\partial \kappa}<0$ if $\gamma<\gamma(\kappa)$. The result then follows from the fact that $\gamma(\kappa)$ is increasing in $\kappa$. Consider

$$
\begin{aligned}
\frac{\partial \Delta p^{*}}{\partial \kappa} & =\frac{\left(\Delta p^{*}\right)^{2}}{n-1} \frac{\partial}{\partial r_{i}}\left[2-r_{i}\left(1+\frac{\gamma n-1}{n-1}\right)-\frac{(\gamma n-1) \frac{2-r_{i}}{n-1}\left(\frac{n}{n-1}-\frac{r_{i}}{1-\gamma}\right)}{\frac{n}{n-1}-\frac{r_{i}}{1-\gamma}+\frac{n-1}{\gamma n-1}}\right] \\
& =\frac{\left(\Delta p^{*}\right)^{2}}{n-1}\left[\frac{\frac{2}{1-\gamma}-\frac{n}{n-1}-\frac{n-1}{\gamma n-1}}{\left(\frac{\kappa}{n-1}+\frac{n-1}{\gamma n-1}\right)^{2}}-1\right] .
\end{aligned}
$$

The term in square brackets in (12) is increasing in $\gamma$. It is positive for $\gamma \rightarrow 1$ and negative for $\gamma \rightarrow \frac{1}{n}$. Hence there exists a unique $\gamma(\kappa) \in\left(\frac{1}{n}, 1\right)$ for which $\frac{\partial \Delta p^{*}}{\partial \kappa}=0$. For $\gamma=\gamma(\kappa)$ the nominator of the term must be positive which implies that it must be decreasing in $\kappa$. Hence $\gamma(\kappa)$ must be increasing.

\section{References}

Borenstein, S. "Price Discrimination in Free-Entry Markets" RAND Journal of Economics, Vol. 16 (1985), pp. 380-397.

Borenstein, S., Rose., N. "Competition and Price Dispersion in the U.S. Airline Industry." Journal of Political Economy, Vol. 102 (1994), pp. 653-83.

Courty, P., Li, H. "Sequential Screening." Review of Economic Studies, Vol. 67 (2000), pp. 697-717.

Courty, P. "Ticket Pricing under Demand Uncertainty." Journal of Law and Economics, Vol. 46 (2003), pp. 627-652.

Dai, M., Liu, Q., Serfes, K. "Is the Effect of Competition on Price Dispersion Non-Monotonic? Evidence from the US Airline Industry" Review of Economics and Statistics, Vol. 96 
(2014), pp. 161-170.

Dana Jr., J. D. "Advance Purchase Discounts and Price Discrimination in Competitive Markets." Journal of Political Economy, Vol. 106 (1998), pp. 395-422.

DeGraba, P. "Buying Frenzies and Seller Induced Excess Demand." RAND Journal of Economics, Vol. 26 (1995), pp. 331-342.

Gaggero, A. A., Piga, C. A. "Airline Market Power and Intertemporal Price Dispersion." Journal of Industrial Economics, Vol. 59 (2011), pp. 552-577.

Gale, I. "Price Dispersion in a Market with Advance-Purchase." Review of Industrial Organization, Vol. 8 (1993), pp. 451-464.

Gale, I., Holmes, T. "Advance-Purchase Discounts and Monopoly Allocation of Capacity." American Economic Review, Vol. 83 (1993), pp. 135-146.

Gerardi, K., Shapiro, A. H. "Does Competition Reduce Price Discrimination? New Evidence from the Airline Industry." Journal of Political Economy, Vol. 117 (2009), pp. 1-34.

Holmes T. "The Effects of Third-Degree Price Discrimination in Oligopoly." American Economic Review, Vol. 79 (1989), pp. 244-250.

Lazarev, J. "The Welfare Effects of Intertemporal Price Discrimination: An Empirical Analysis of Airline Pricing in U.S. Monopoly Markets" Unpublished manuscript, (2013).

Möller, M., Watanabe, M. "Advance Purchase Discounts versus Clearance Sales." Economic Journal, Vol. 547 (2010), pp. 1125-1148.

Möller, M., Watanabe, M. "Competition in the Presence of Individual Demand Uncertainty." RAND Journal of Economics, (2016) forthcoming.

Nocke, V., Peitz, M., Rosar, F. "Advance-Purchase Discounts as a Price Discrimination Device." Journal of Economic Theory, Vol. 146 (2011), pp. 141-162.

Stavins, J. "Price Discrimination in the Airline Market: The Effect of Market Concentration." Review of Economics and Statistics, Vol. 83 (1996), pp. 200-202. 


\section{Figures}
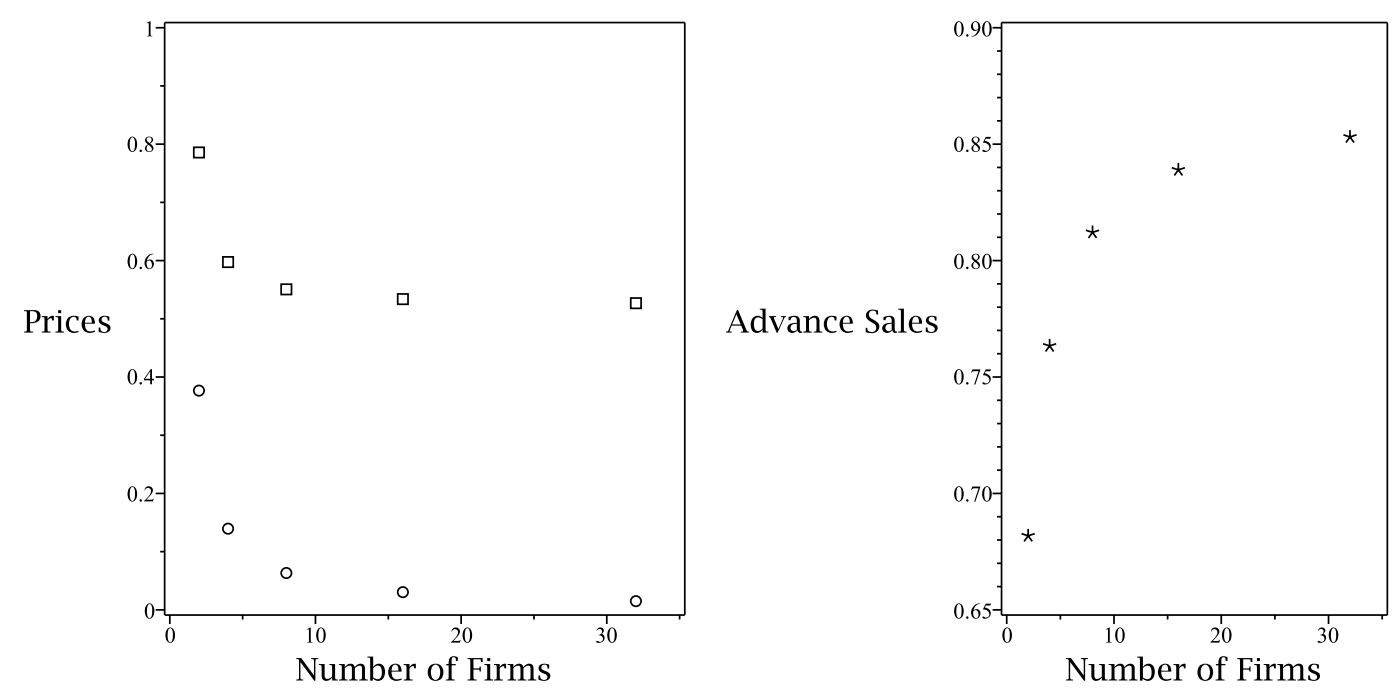

Figure 1: High uncertainty $\gamma=0.4$. Numerical example with $n=64$ products and $m \in\{2,4,8,16,32\}$ firms. Prices $p_{1}^{*}$ (circles), $p_{2}^{*}$ (squares), and the fraction of advance sales $\sigma_{W}^{*}=\frac{p_{2}^{*}-p_{1}^{*}}{1-\gamma}$ (asterisks) in dependence of the number of competitors.
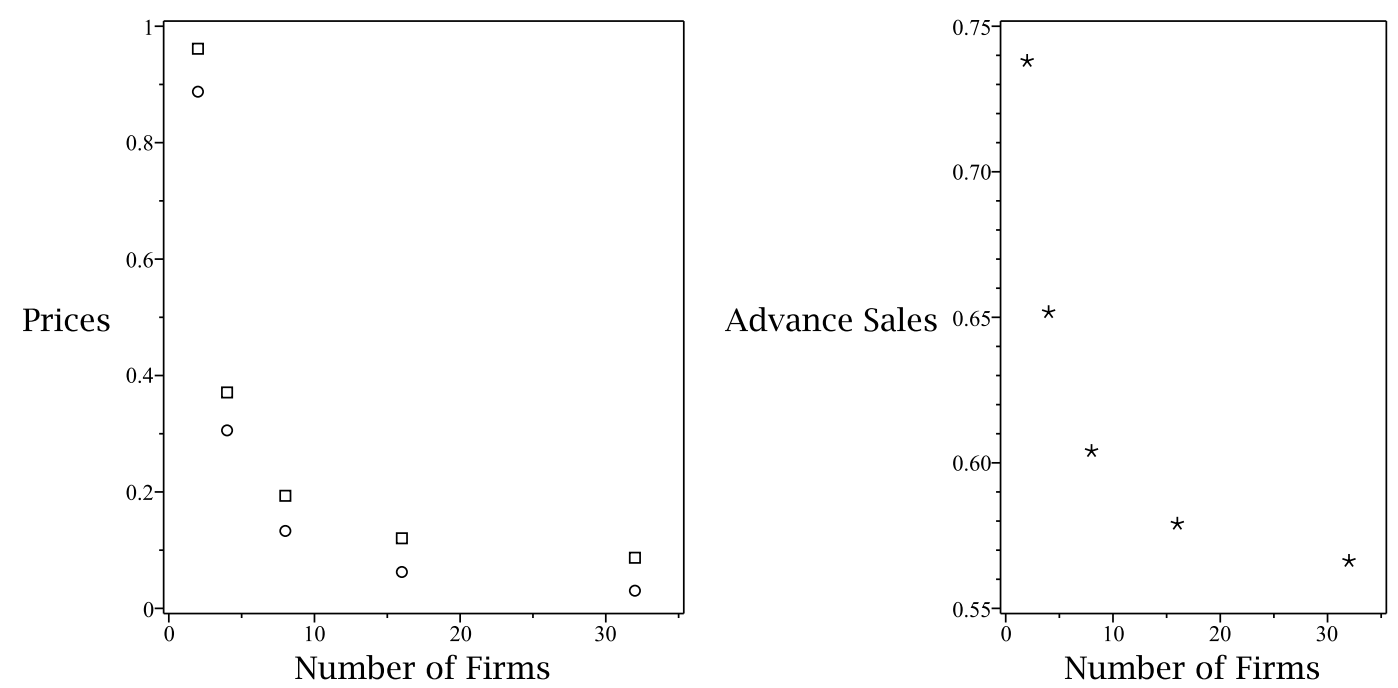

Figure 2: Low uncertainty $\gamma=0.9$. Numerical example with $n=64$ products and $m \in\{2,4,8,16,32\}$ firms. Prices $p_{1}^{*}$ (circles), $p_{2}^{*}$ (squares), and the fraction of advance sales $\sigma_{W}^{*}=\frac{p_{2}^{*}-p_{1}^{*}}{1-\gamma}$ (asterisks) in dependence of the number of competitors. 